\title{
Epidemiological study of surgical cases between 2000-2012 at the Hospital of Gastrointestinal and Liver disease in Baghdad city
}

\author{
Rawah . A. Faraj (M.S.C.) ${ }^{1,}$ and Salwa .S. Muhsin (Ph.D.) ${ }^{2}$ \\ Department Of Community Health / Institute Of Technical Medicine Foundation Of Technical Education \\ Baghdad-Iraq
}

\begin{abstract}
This study was conducted to evaluate retrospectively(607) patient diagnosed with hydatid cyst disease and treated surgically at the hospital of gastrointestinal and liver disease between 2000-2012 in Baghdad city . cysticEchinococcosis affected more females 359 (59.14\%) than males 248(40.85\%).

A remarkable gender differences showed towards females was observed and the male / female ratio among cystic Echinococcosis cases $\leq 21$ and $\geq 70$ years old was $(29.48 \%)$ and $(1.64 \%)$ respectively. the age of patient ranged (0-<70)years old and the age group (21-30), (31-40), years were the most affected.

Housewives had the highest rate of infection (51.40\%) followed by workers in different occupations which showed a significant differences $(p<0.001)$. similarly rural dwellers was also over - respected among the cases (51. 40\%), (48.59\% urban).
\end{abstract}

Keywords: parasitic diseases ,Echinococcosis, Zoonotic disease , Echinococcusgranulosis, Hydatidcyct.

\section{Introduction}

Echinococcosis is one of the major zoonotic parasitic disease that occurs throughout the world and causes considerable economic losses and public health problems in many countries. Given that sheep acts as intermediate and dogs as definitive host of echinococcusegranulosus, hydatidosis poses both a human health risk and an economic loss to the country . hydatid cysts can grow in any site of human body, but the most common locations are the liver ( $65 \%)$ and the lung (25\%) (1) .

Human contamination take accidentally place through close contact with an infected dog and human is usually a dead - end for the parasite .Hydatid cysts are maintained in three district cycles, a livestock, dog domestic cycle (sheep, cattle, goats and equines) . a desert cycle between dogs and camels and wild cycle between wild carnivores and wild ruminants (2)

Many studies have shown the disease in Iraq is endemic $(3,4,5)$ and enzootic in nature in central and northern parts of Iraq ( 6). Surgical confirmed cases of human hydatidosis have been studied in Basrah ,Mousl, Baghdad and Erbil $(7,8,3)$.

And in many parts of the world especially in the rural areas, were the sheep and cattle are raised ( 9 , 10) . Other researches investigated in Iraq, have reported on the common occurrence of adult Echinococcusgranulosusin the stray dog $(11,9)$. ultrasound is the most useful non invasive diagnostic tool and is also used to classify the cysts $(12,13)$.

This study was of its type to be carried out to determine the level of infections in hospitalized patient with hydaditosis in Iraq for the period $(2000-2012)$.

\section{Research Methods}

This study was carried out in patients cases of hydatidosis in hospital of gastrointestinal and liver disease in Baghdad city were analyzed based on medical documents of patients, who were operated in this hospital, these patients were operated lived in different sites of Iraq .

Profile of patients including age, sex , living area, location of this cyst and time of there surgery were recorded for each patient the ratios between male and female cases during 01/01/ 2000 to 31/ 12/ 2012 which recorded in SPSS 14 statically software .

\section{Result and Discussion}

Six hundred and seven cases of human hydatidosis were operated in digestive disease in Baghdad decidedly surgically confirmed over the period 01/01/ 2000 to 31/12/ 2012 . having contracted hydatidosis table (1)

Table (1) hydatid patient admitted to hospital during 2000- 2012 according to sex .

\begin{tabular}{|c|c|c|}
\hline Sex & Number of infections & Percentage \\
\hline Male & 248 & $40.86 \%$ \\
\hline Female & 359 & $59.14 \%$ \\
\hline Total & 607 & $100 \%$ \\
\hline
\end{tabular}


Hydatidosis is a worldwide health problem as a result of increased travel and emigration (14) . it is endemic in Iraq and most countries of the middle east . it is a major economic and public health problem in causing a great morbidity and mortality . which is attributed in most of the cases to cyst complications $(15,16)$.

Female were effected more than male the males probably because in the rural area, the females are usually involved in dealing with the animals and they don't care to disinfect their contamination food and vegetables (17).

Table (2) Distribution of hydtidosis infection according to sex and the years

\begin{tabular}{|c|c|c|c|}
\hline & Male \% & Female \% & Total \% \\
\hline 2000 & $0(\% 0)$ & $1(0.27)$ & $1(0.16)$ \\
\hline 2001 & $12(4.83)$ & $20(5.57)$ & $32(5.27)$ \\
\hline 2002 & $15(6.04)$ & $19(5.29)$ & $43(5.60)$ \\
\hline 2003 & $24(9.67)$ & $29(8.07)$ & $53(8.73)$ \\
\hline 2004 & $16(6.45)$ & $25(6.96)$ & $41(6.75)$ \\
\hline 2005 & $26(10.48)$ & $42(11.69)$ & $68(11.20)$ \\
\hline 2006 & $27(10.88)$ & $38(10.58)$ & $65(10.70)$ \\
\hline 2007 & $17(6.85)$ & $27(7.52)$ & $44(7.26)$ \\
\hline 2008 & $13(5.24)$ & $25(6.69)$ & $38(6.20)$ \\
\hline 2009 & $21(8.46)$ & $27(7.52)$ & $48(7.90)$ \\
\hline 2010 & $24(9.67)$ & $37(10.30)$ & $61(10.04)$ \\
\hline 2011 & $20(8.06)$ & $32(8.91)$ & $52(8.56)$ \\
\hline 2012 & $33(13.3)$ & $37(10.30)$ & $70(11.53)$ \\
\hline Total & $248(40.85) \%$ & $359(59.14) \%$ & 607 \\
\hline
\end{tabular}

The highest number of hydatidosis cases 70(11.53\%), 68(11.20\%), 65(10.70\%) was recorded in 2012,2005 , 2006,2010 respectively and the lowest $1(0.16 \%)$ in 2000 .

Table (3) Distribution of hydatidosis infection according to age group

\begin{tabular}{|c|c|c|}
\hline & & \\
Age group & Male and female & Percentage $\%$ \\
\hline $0-10$ & 10 & $(1.64)$ \\
\hline $11-20$ & 62 & $(10.21)$ \\
\hline $21-30$ & 179 & $(29.48)$ \\
\hline $31-40$ & 132 & $(21.74)$ \\
\hline $41-50$ & 88 & $(14.49)$ \\
\hline $51-60$ & 93 & $(15.32)$ \\
\hline $61-70$ & 33 & $(3.43)$ \\
\hline $70>$ & 10 & $(1.64)$ \\
\hline Total & 607 & 100 \\
\hline
\end{tabular}

These ages of hydatidosis patients range from $0 \geq 70$ years, table (3) shown that age prevelance increased from $(29.48 \%)$ in this aged (21-30) years or less $(1.64 \%)$ for those $(0-10)$ years or above 70 years .

Table (4) number of hydatidosis cases according to living country

\begin{tabular}{|c|c|c|}
\hline Country & Number of hydatidosis cases & Percentage \\
\hline Urban & 295 & $48.59 \%$ \\
\hline Rural & 312 & $51.40 \%$ \\
\hline Total & 607 & 100 \\
\hline
\end{tabular}

In the current survey most of the hydatidosis cases were in middle - aged - similar observation have been made in Iraq (18). Cystic echinococcosis is a chronic disease and hydatid cyst grow very slowly in human when compared to animals . it takes years for a hydatid cyst to bring on the clinical disease in human host . this might explain the reasons for high rate of surgeries for hydatid cyst in people who are in the age group 21-40 years old. These finding are in line with other studies $(19,20,21)$.

More contact with contamination soil handling and eating contaminated raw vegetables and meet imposed an important factor to cause more infection in housewives of the region . this result is similar to those reported ( 22,23).

The result showed that the prevalence of hydatidosis in the rural dwellers was significantly higher than the urban dwellers (51.40\%, rural , 48.59\% , urban ) (19.24). 


\section{Conclusion}

In conclusion hydatidosis remains an important health problem in many area of Iraq including Baghdad province . the finding of this study hent for more extensive epidemiological investigations of hydatidosis in human to determine the prevalence, economic impact and risk factors of the disease in this area, effective programs need to be implemented for controlling and reducing the disease in live stock, carnivores especially dogs and also human in the region .

\section{Reference}

[1]. RostamiNajad M . Jahani - Sherafat S. CherghipourK , et al ; Hydatic cyst prevalence in slaughtered animals ; A neglected health problem . J. paramed . sci. 3(3) (2012) : 25-29

[2]. HeidariZ ., MohebaliM .Zarei Z., et al ., Seroepidemeological study of human hydtidosis in Meshkinshahr district Ardabil province. Iran - Iran J. parasitol . 6(3) (2011): 19-25 .

[3]. Mahdi K. .Benyan Z. AL -Nowfial J. Hepatic hydatidosis in Man and his livestock in southern Iraq . Japanses Journal of tropical medicine and hygiene. (1987) : 2-11

[4]. Benyan Z. , and Mahdi K. Pulmonary hydatidosis in man and livestock in southern Iraq . Saudi Medical Journal . 8(4) (2004 ): 402 406 .

[5]. Al- BarwariE ., Saeed S. , Khalid W., Al - Harmani L. Human hydatidosis in Arbil , N . Iraq . Journal of Islamic academy of sciences . 4(4) (1999) : $330-335$

[6]. Al- Abassy N., Altif I ., Jawad K. , and Al- Sagur M. the prevalence of hydatid cysts in slaughtered animals in Iraq . Annals of Tropical medicine and parasitology $74 ;(1980): 185-187$.

[7]. Mahmoud S. Studies on hydatid disease in Mousl . MSc. Thesis, University of Mousl Iraq .(1980).

[8]. Al- Sakar N. Human hydatid disease in Mousl Iraq . Medical Journal . 29 (1980): 80- 86

[9]. Turner JA .Cestodes I. FeiginRD, Cherry D, Demmler GI, Kaplan L . Textbook of Pediatric infectious disease . $5^{\text {th }}$ ed . WB Sannders . (2004): $2797-2816$

[10]. Miabi Z., Hashemi H , Ghaffarpour M., Ghelichnia H. Media R . clinic radiological findings and treatment outcome in patient with intracranial hydatid. Acta .MedicaIranica . 43 ( 2005): 359

[11]. Blanton R ., Behrman RE ., KliegmanRM ., J enson HB . Echinococcosis .eds. Nelson textbook of pediatrics . $17^{\text {th }}$ ed .Philadelphia , : WB Saunders . (2004) : $1173-1174$.

[12]. RamtinHadighi ,FatemehMihadi\& Mohammad BayherRokni . Evaluation of adot - ELISA for the Serodiagnosis of human hydatiad disease. Pak. J . Med - Sci . 19 (4) (2003) : 268-271

[13]. Biava MF. Dao A. Fortier B. Laboratory diagnosis of CysticHydatid disease world . J . Surg. (25) (2001) : 10-14 .

[14]. RidvarSeven ,Eren Berber, SecukMercan, etal. Laparoscopic treatment of hepatic hydatidcysts . Surgery.128 (1) (2000) : $236-240$.

[15]. Ahmed R. Al Bahran :, Mohammed, A. Al- Maiyah, Zuhair R. Al- Bahrani . survey of Abdominal Hydatidosis , Review of (791) Patients in Iraq . Arab Journal of Gastroenterology . 4(2) October (2003) : 151- 156

[16]. Asakkal N. Human Hydatid disease in Mousl . Iraq Med. J. (29) (1982) : 80- 86

[17]. Zeki A- Al - Fadgh ,Mazin H . Al - Hawaz, wadah, M, Al - Badir , Complicated hydatid cyst in Basra . Iraq Journal of Gastroenterology . . 1(2) (2002) : 27-31 .

[18]. Amer H.H and Raafat . R .Ahmed. Review of 150 case of hepatic hydatid cyst . J. GE .6(1) 2006.

[19]. Saeed, I ., Kapel . C. ,Saida, L.A., Willingham, L. and Nansen, P. Epidemiological of Echinococcusgranulosus in Arbil Province , northern Iraq . 1990- 1998 .Journal of Helminthology (74 )(2000): 83-88.

[20]. Pezeshki, A. Kia, E.B. Gholizadeh, A. \&Koohzare , A. An analysis of hydatid cyst surgeries in TehranMiladhospitacal , Iran during 2001-2004 . Pakistan Journal of Medical Sciences . 23 (2007) : 138- 140

[21]. Al - Qaoud K. M. Craig , P.S. and Abdel - Hafex , S.K. Retrospective Surgical incidence and case distribution of cystic echinococcosis in Jordan between 1994- 2000 . ActaTropica . (87)(2003) : 207 - 214.

[22]. Ahmedi , N . \&Dalimi, A. characterization of Echinococusgrnulosus isolates from human sheep and camel in Iran . infection , Genetics and Evolution .(6) (2006) : 85- 90

[23]. Sarkari, B. , Sadijaoi , SM . Behestian, M.N ., Aghaee, M. \&Sedaghat, F. Human Cystic Echinococcosis inYasnj district in Southwest of Iran : an epidemiological study of seroprevelance and surgical cases over a- ten year period. Zoonoses public health (57) (2010) : 146- 150 .

[24]. Pierangel, N.B. , Soriano, S.V. Roccia , I ., Gimenez J. Lazzarini, L.E. Grenovero, M.S., Menestrina , C. \&Basualdo, J.A. Heterogeneous distribution of human cystic echinococcosis after a long - term control program in Neguen. PathogeniaArgentenia(56)(2007) : 149- 155 . 